OPEN ACCESS

Edited by: Aasef G. Shaikh,

Case Western Reserve University, United States

Reviewed by: Elena Pretegiani, National Eye Institute $(\mathrm{NIH})$, United States Michael Morgan,

University Hospitals of Cleveland, United States

*Correspondence:

Ali G. Hamedani ali.hamedani@uphs.upenn.edu

Specialty section: This article was submitted to Neuro-Ophthalmology, a section of the journal Frontiers in Neurology

Received: 09 March 2017 Accepted: 23 June 2017 Published: 18 July 2017

Citation: Hamedani AG and Gold DR (2017) Eyelid Dysfunction in Neurodegenerative, Neurogenetic, and Neurometabolic Disease.

Front. Neurol. 8:329. doi: 10.3389/fneur.2017.00329

\section{Eyelid Dysfunction in Neurodegenerative, Neurogenetic, and Neurometabolic Disease}

\author{
Ali G. Hamedani ${ }^{1 *}$ and Daniel R. Gold $d^{2,3,4,5}$ \\ ${ }^{1}$ Department of Neurology, Hospital of the University of Pennsylvania, Philadelphia, PA, United States, ${ }^{2}$ Department \\ of Neurology, Johns Hopkins Hospital, Baltimore, MD, United States, ${ }^{3}$ Department of Ophthalmology, Johns Hopkins \\ Hospital, Baltimore, MD, United States, ${ }^{4}$ Department of Neurosurgery, Johns Hopkins Hospital, Baltimore, MD, \\ United States, ${ }^{5}$ Department of Otolaryngology - Head and Neck Surgery, Johns Hopkins Hospital, Baltimore, MD, \\ United States
}

Eye movement abnormalities are among the earliest clinical manifestations of inherited and acquired neurodegenerative diseases and play an integral role in their diagnosis. Eyelid movement is neuroanatomically linked to eye movement, and thus eyelid dysfunction can also be a distinguishing feature of neurodegenerative disease and complements eye movement abnormalities in helping us to understand their pathophysiology. In this review, we summarize the various eyelid abnormalities that can occur in neurodegenerative, neurogenetic, and neurometabolic diseases. We discuss eyelid disorders, such as ptosis, eyelid retraction, abnormal spontaneous and reflexive blinking, blepharospasm, and eyelid apraxia in the context of the neuroanatomic pathways that are affected. We also review the literature regarding the prevalence of eyelid abnormalities in different neurologic diseases as well as treatment strategies (Table 1).

Keywords: eyelid, neurodegenerative diseases, neurogenetic, blinking, blepharospasm, Parkinson, movement disorders

\section{PTOSIS}

\section{Overview of Eyelid Elevation}

During wakefulness, the muscles of eyelid elevation are tonically activated to maintain eye opening against the passive tendency of the eyelids to close, and the muscles of eyelid closure are silent except during blinks. Thus, ptosis is by definition a problem of reduced eyelid elevation rather than excess eyelid depression.

The primary muscle of upper eyelid elevation is the levator palpebrae superioris (LPS), which is innervated by the oculomotor nerve. It originates from the lesser wing of the sphenoid bone at the orbital apex, courses through the orbit superior to the superior rectus (SR) muscle, and inserts on the superior tarsal plate as well as directly on the skin of the upper eyelid, forming the lid crease. A secondary muscle (the superior tarsal muscle, also known as Müller's muscle) originates from the distal aponeurosis of the LPS and inserts on the superior tarsal plate as well. In the lower eyelid, the inferior tarsal muscle analogously inserts on the inferior tarsal plate. The tarsal muscles are both innervated by oculosympathetic nerve fibers arising from the superior cervical ganglion. The frontalis and other facial nerve-innervated muscles can indirectly affect eyelid position as well (Figure 1).

Several clinical measurements can aid in the localization and assessment of ptosis (1):

1. Palpebral fissure height, which is the distance between the upper and lower eyelids at rest in primary gaze and is normally at least $10 \mathrm{~mm}$. This can be subdivided into the margin reflex 
TABLE 1 | Summary of eyelid disorder mechanisms, associations, and treatments in neurodegenerative and neurogenetic disease.

\begin{tabular}{|c|c|c|c|}
\hline Eyelid disorder & Mechanism(s) & Associated conditions & Treatment(s) \\
\hline \multirow[t]{3}{*}{ Ptosis } & LPS weakness & $\begin{array}{l}\text { CPEO spectrum, myotonic dystrophy, } \\
\text { OPMD, congenital myasthenic } \\
\text { syndromes, SCA28 }\end{array}$ & $\begin{array}{l}\text { Eyelid taping and crutches, } \\
\text { surgical myectomy or frontalis } \\
\text { suspension }\end{array}$ \\
\hline & $\begin{array}{l}\text { LPS fibrosis, dysgenesis, } \\
\text { or dehiscence }\end{array}$ & Congenital ptosis, CFEOM & \\
\hline & Oculosympathetic dysfunction & $\begin{array}{l}\text { Congenital disorders of } \\
\text { neurotransmitter synthesis }\end{array}$ & \\
\hline Eyelid retraction & $\begin{array}{l}\text { Dissociation between eye } \\
\text { and eyelid position due to impaired } \\
\text { supranuclear control of the } \\
\text { M-group resulting in excess CCN activity }\end{array}$ & PSP, SCA3 & $\begin{array}{l}\text { Ocular lubrication to prevent exposure } \\
\text { keratopathy due to increased } \\
\text { corneal exposure }\end{array}$ \\
\hline Decreased blinking & $\begin{array}{l}\text { Reduced nigrocollicular pathway } \\
\text { activity resulting in greater inhibition } \\
\text { of spontaneous blinking }\end{array}$ & Parkinsonism (PSP > PD) & $\begin{array}{l}\text { Ocular lubrication; dopaminergic } \\
\text { therapy to treat underlying } \\
\text { movement disorder }\end{array}$ \\
\hline Increased blinking & $\begin{array}{l}\text { Increased nigrocollicular pathway } \\
\text { activity resulting in reduced inhibition } \\
\text { of spontaneous blinking }\end{array}$ & Hyperdopaminergic disorders (e.g., HD) & $\begin{array}{l}\text { Dopaminergic blockade or reduction } \\
\text { to treat underlying movement disorder }\end{array}$ \\
\hline Blepharospasm & Blink reflex hyperexcitability & $\begin{array}{l}\text { Idiopathic, with or without eyelid apraxia; } \\
\text { Meige syndrome and other dystonias; } \\
\text { parkinsonism (PSP >> PD); SCAs }\end{array}$ & $\begin{array}{l}\text { Botulinum toxin, polarized lenses, } \\
\text { surgical myectomy (especially } \\
\text { if comorbid eyelid apraxia) or DBS }\end{array}$ \\
\hline Eyelid apraxia & $\begin{array}{l}\text { Excess supranuclear LPS inhibition } \\
\text { with or without pretarsal OO activation }\end{array}$ & $\begin{array}{l}\text { Idiopathic, with or without blepharospasm; } \\
\text { parkinsonism (PSP > MSA > PD); ALS }\end{array}$ & $\begin{array}{l}\text { Botulinum toxin (specifically to } \\
\text { pretarsal OO), eyelid crutches or } \\
\text { goggles, trial of levodopa or other } \\
\text { medications, rarely surgical myectomy } \\
\text { frontalis suspension (especially if } \\
\text { comorbid blepharospasm) }\end{array}$ \\
\hline
\end{tabular}

LPS, levator palpebrae superioris; CPEO, chronic progressive external ophthalmoplegia; OPMD, oculopharyngeal muscular dystrophy; CFEOM, congenital fibrosis of the extraocular muscles; SCA, spinocerebellar ataxia; CCN, central caudal nucleus; PSP, progressive supranuclear palsy; SC, superior colliculus; PD, Parkinson's disease; HD, Huntington's disease; DBS, deep brain stimulation; OO, orbicularis oculi; MSA, multiple systems atrophy; ALS, amyotrophic lateral sclerosis.

distance (MRD) 1, which is the distance between the corneal light reflex and the upper eyelid margin, and the MRD 2, which is the distance between the corneal light reflex and the lower eyelid margin.

2. Lid crease height, which is the distance between the lid crease and upper eyelid margin as measured in downgaze and is normally less than $10 \mathrm{~mm}$. The most common cause of ptosis with heightened lid crease is the levator dehiscence-disinsertion syndrome (see below).

3. Eyelid excursion or levator function, which is the difference in position of the upper eyelid margin in upgaze compared to downgaze and is normally greater than or equal to $12 \mathrm{~mm}$.

Of these parameters, perhaps the most useful is eyelid excursion, as it differentiates ptosis with reduced levator function from ptosis with preserved levator function. Ptosis with reduced levator function implies a lesion of the LPS or its motor control.

\section{Ptosis due to Levator Weakness}

Because it is very rich in mitochondria (2), the LPS is preferentially affected in mitochondrial myopathies. This is illustrated by the prominent ptosis that accompanies the chronic progressive external ophthalmoplegia (CPEO) phenotype, which can occur in isolation or in association with other mitochondrial syndromes, such as the Kearns-Sayre syndrome, sensory ataxic neuropathy with dysarthria and ophthalmoplegia, Leigh syndrome, and mitochondrial neurogastrointestinal encephalopathy among others (3). CPEO can be caused by either mitochondrial or nuclear DNA mutations (4). When the mitochondrial genome is affected by large deletions, rearrangements, or point mutations involving genes encoding for tRNA synthetases, mutations are typically somatic rather than germline, resulting in a sporadic rather than maternal pattern of inheritance. Mutations in nuclear genes can also cause $\mathrm{CPEO}$ and may be inherited in an autosomal dominant or recessive manner. To further complicate matters, many of these nuclear genes (e.g., OPA1) are responsible for mitochondrial homeostasis, and thus patients with inherited nuclear DNA mutations can acquire somatic mitochondrial DNA mutations over time (5). This may account for some of the phenotypic variability of these diseases. Ptosis and ophthalmoparesis may also be seen in some of the autosomal dominant spinocerebellar ataxias (SCAs) (6), particularly SCA28, which is caused by mutations in the AFG3L2 gene (7). Interestingly, SCA28 patients have been shown to accumulate mitochondrial DNA mutations (8), suggesting a mechanism for which ptosis might appear in an otherwise purely cerebellar and pyramidal syndrome. A CPEO-like syndrome accompanied by symmetric parkinsonism has been reported in families with c10orf2 (Twinkle) and POLG1 mutations (9), and ptosis has also occurred in cases of early-onset Parkinson's disease (PD) due to PARK2 mutations (10). Otherwise, ptosis is not a 


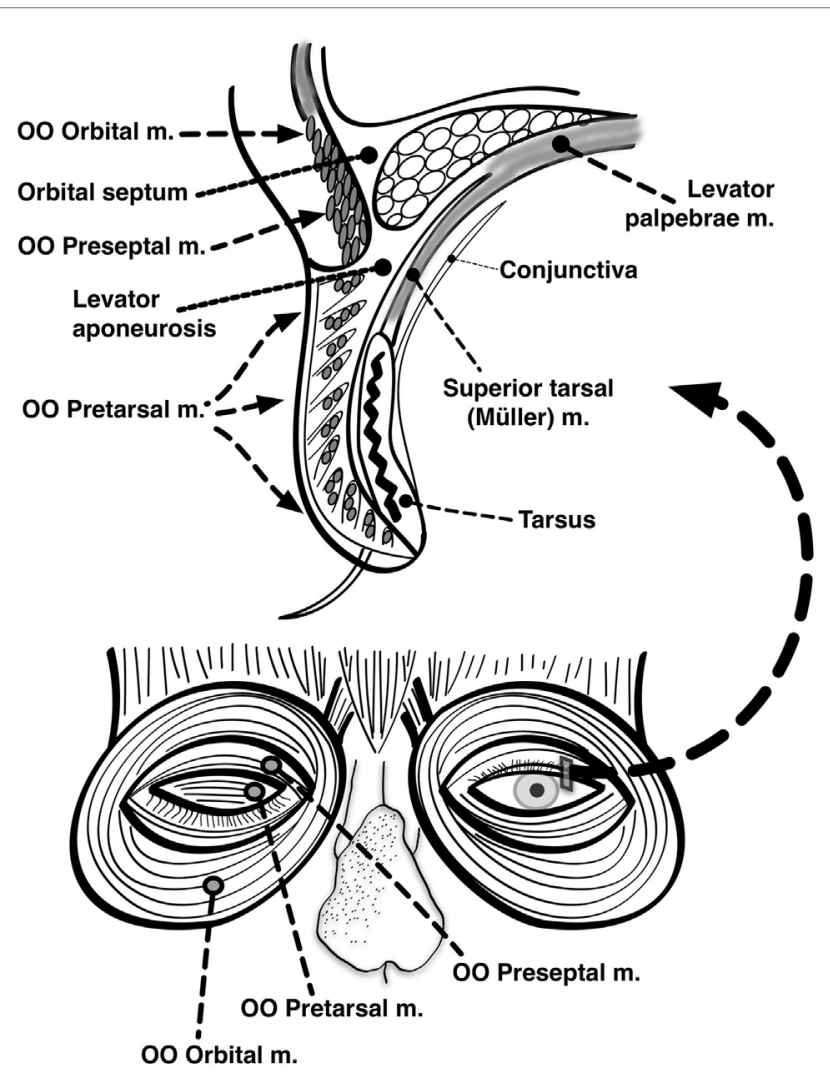

FIGURE 1 | Anatomy of the eyelids. Seen here are the major muscles of eyelid opening and closure. The levator palpebrae, which is innervated by the oculomotor nerve, inserts on the tarsus via the levator aponeurosis and directly on the skin of the upper eyelid. The superior tarsal muscle (also known as Muller's muscle, which is innervated by oculosympathetic fibers) originates from the levator aponeurosis and inserts on the tarsus. The orbicularis oculi $(\mathrm{OO})$ is innervated by the facial nerve. It is made up of two portions: one contained within the eyelid itself (palpebral portion) and one located outside the eyelid surrounding the orbit (orbital portion). The palpebral portion of the $\mathrm{OO}$ can be further subdivided into preseptal and pretarsal components based on its anatomic location relative to the tarsus (Modified with permission from (154), Figure 24.5).

typical manifestation of PD or other acquired neurodegenerative disorders.

Most other inherited myopathies spare the eyelids and extraocular musculature. Notable exceptions include oculopharyngeal muscular dystrophy (OPMD) and myotonic dystrophy. The pathologic hallmark of OPMD on muscle biopsy is filamentous intranuclear inclusions composed of the misfolded polyalanine expanded $P A B P N 1$ protein [which is similar to other trinucleotide repeat diseases such as Huntington's disease (HD)], though aggregates of dysmorphic mitochondria have also been observed (11), which may be the mechanism by which the LPS is preferentially affected. A striking feature of myotonic dystrophy is that while it is an autosomal dominant disease, the phenotype is more severe when it is inherited maternally rather than paternally, and congenital presentations are seen exclusively in the children of affected mothers (12). These observations led to the hypothesis that the pathogenesis of myotonic dystrophy may be influenced by mitochondrial factors. However, several mitochondrial DNA sequencing studies have failed to detect any variants associated with phenotype severity (13). Congenital myasthenic syndromes also frequently cause ptosis. They are caused by mutations in a number of genes involved in neuromuscular transmission, both presynaptic and postsynaptic (14).

\section{Congenital Ptosis}

Reduced levator function that is present at birth has a separate differential diagnosis, namely that of dysgenesis or fibrosis of the eyelid musculature. Isolated congenital ptosis is caused by dysgenesis and hypoplasia of the LPS, and typical clinical features include reduced or absent lid crease and lid lag in downgaze. Due to its shared embryologic origin with the SR, upgaze may also be affected (15). Most cases of congenital ptosis are unilateral and sporadic, but mutations in several genes have been identified in familial cases (16). Histologic examination reveals reduced muscle fiber number and fibrosis, leading many to initially suspect that the disease is primarily myopathic in pathogenesis (17). However, increasing recognition of aberrant reinnervation in these cases, including the Marcus-Gunn jaw winking phenomenon (whereby a ptotic eyelid retracts with lateral jaw movement as in sucking or chewing, suggesting innervation of the LPS by the trigeminal nerve), has led to dysinnervation-based theories, and some, therefore, group congenital ptosis with the congenital cranial dysinnervation disorders (CCDD) (18). Congenital fibrosis of the extraocular muscles is another CCDD that is thought to have a similar pathophysiology and produces a syndrome of ptosis and ophthalmoplegia that resembles CPEO except that it is present at birth and the ophthalmoplegia is restrictive in physiology (19). Of note, aberrant extraocular muscle innervation can produce secondary eyelid abnormalities without directly affecting the LPS. For example, in the Duane retraction syndrome, the palpebral fissure narrows during adduction not because of reduced eyelid opening or increased eyelid closure but because of simultaneous contraction of the medial and lateral recti due to dual innervation by the oculomotor nerve resulting in retraction of the globe into the orbit (20).

\section{Mechanical Ptosis}

Ptosis with preserved levator function is usually caused by a defect of the aponeurotic insertion of the LPS onto the upper eyelid. Levator dehiscence-disinsertion syndrome is the most common cause of acquired ptosis in adulthood and occurs when the LPS loses its insertion site on the superior tarsal plate and then reinserts on a more proximal portion of the tarsal plate or eyelid skin. This results in an abnormally increased lid crease height with preserved eyelid excursion (21). It is commonly seen with advancing age but can be accelerated by eyelid manipulation during regular contact lens use, frequent rubbing of the eyes, botulinum injection of the orbicularis oculi $(\mathrm{OO})$ for the treatment of blepharospasm (22), or ocular surgery. Ptosis with preserved levator function can be inherited in relative isolation as in the autosomal dominant blepharophimosis-ptosis-epicanthus inversus syndrome (BPES) or in the setting of other craniofacial abnormalities as in trisomy 13, Turner syndrome, Noonan syndrome, Cornelia de Lange syndrome, and many of the congenital arthrogryposes (23). 
As discussed later in this review, the level of tonic LPS activity depends on vertical eye position. By contrast, the superior and inferior tarsal muscles remain equally active in all directions of gaze; they are not primary eyelid elevators but instead are modulated by level of arousal and sympathetic tone. Thus, a lesion of the tarsal muscles or their oculosympathetic innervation (as in Horner's syndrome) results in mild to moderate ptosis with preserved levator function rather than the more severe ptosis with reduced levator function that is seen in true LPS weakness of neurogenic (e.g., oculomotor nerve palsy) or myogenic origin. The ptosis seen in disorders of neurotransmitter synthesis, such as tyrosine hydroxylase deficiency, aromatic L-amino acid decarboxylase deficiency, dopamine betahydroxylase deficiency, and brain dopamine-serotonin vesicular transport disease is thought to occur by this mechanism (24).

\section{Treatment of Ptosis}

Symptomatic treatment of ptosis is generally reserved for cases where the degree of ptosis is so great as to obscure the visual field or cause cosmetic distress. Conservative measures include temporary taping of the upper eyelids or the use of crutches attached to eyeglasses. Surgical options include shortening of the LPS, resection of the superior tarsal muscle, and frontalis suspension to elevate the entire upper eyelid complex. Other than the usual risks of any surgical procedure, the primary risk associated with surgical treatment of ptosis is incomplete eyelid closure during normal blinking and sleep (lagophthalmos) causing exposure keratopathy. Surgery should, therefore, be approached with caution especially if the muscles of eyelid closure are also weak, as in CPEO and other myopathies.

\section{EYELID RETRACTION}

\section{Overview of Vertical Eye and Eyelid Position Coordination}

To maximize protection of the cornea and tear film while avoiding obscuration of the visual field, the eyelids normally elevate in upgaze and depress in downgaze with a velocity and gain that roughly matches that of the corresponding eye movement, be it a saccade or smooth pursuit (25). A single nucleus [the central caudal nucleus (CCN) of the midbrain] is shared by both the left and right oculomotor nucleus complexes and innervates both LPS muscles; eyelid elevation is, thus, yoked between the two eyes (26). In electrophysiologic studies of primates, the $\mathrm{CCN}$ has a basal firing rate in primary gaze, and in upward saccades, it experiences a burst of increased firing after which its basal rate resumes $(25,27,28)$. Correspondingly, in downward saccades, it experiences a pause in firing, during which the eyelid passively depresses until it reaches its target level, at which point the basal firing rate resumes. Similar firing patterns have been recorded in the SR subnucleus during vertical saccades, suggesting shared supranuclear control with the CCN $(28,29)$. In primates, a population of neurons called the M-group lying adjacent to the rostral interstitial nucleus of the median longitudinal fasciculus (riMLF, which generates vertical and torsional saccades) sends projections to both the CCN and the oculomotor subnuclei responsible for supraduction (namely, the SR and inferior oblique) (30). It appears to receive excitatory input from the riMLF and superior colliculus (SC) during upgaze and inhibitory input from the interstitial nucleus of Cajal (iNC) and nucleus of the posterior commissure (nPC) during downgaze (31) (Figure 2).

\section{Eyelid Retraction in Midbrain Dysfunction}

Disruption of these midbrain pathways is the mechanism by which central nervous system disease causes eyelid retraction. It is often accompanied by a vertical gaze palsy, as in the dorsal midbrain syndrome (also known as the pretectal or Parinaud syndrome, where eyelid retraction is referred to as Collier's sign) (32) and progressive supranuclear palsy (PSP). Eyelid retraction in these disorders reflects a dissociation between eye position and eyelid position such that the CCN is relatively overactivated. This may be due to overstimulation of the M-group in an attempt to overcome an upgaze palsy. This hypothesis, which presumes that supranuclear input is reduced to the SR subnucleus but preserved to the CCN, is supported by the fact that eyelid retraction is often more prominent during attempted upgaze, when M-group excitation is expected to increase. Alternatively, eyelid retraction may be due to an underinhibition of the M-group by the iNC and nPC. Supportive of this hypothesis is the observation of lid lag (a failure of the eyelids to lower sufficiently during attempted downgaze, when inhibitory input to the M-group should be greatest) in some patients with eyelid retraction.

\section{Neurodegenerative Diseases Associated With Eyelid Retraction}

Eyelid retraction is seen in virtually all patients with PSP (33) and is said to result in a characteristic surprised appearance or "stare." By contrast, it has only been rarely reported in PD (34). Eyelid retraction is also a classic finding in SCA3 (also known as Machado-Joseph disease); in one study, $65 \%$ of patients with SCA3 had eyelid retraction resulting in a "bulging eyes" appearance compared to less than $5 \%$ of patients with other autosomal dominant SCAs (35). Interestingly, while midbrain atrophy is the pathologic hallmark of PSP, it is rarely seen in SCA3.

\section{Lid Nystagmus}

The close relationship between vertical eye and eyelid position applies even when eye movement is involuntary, as in upbeat nystagmus (UBN). Occasionally, rhythmic movements of the eyelids can be seen without visible UBN, resulting in the so-called eyelid nystagmus or lid flutter (36). The same mechanisms by which eye and eyelid position become dissociated in eyelid retraction are probably also responsible for the absence of eye movement in eyelid nystagmus, which is often associated with midbrain ischemic and compressive lesions $(37,38)$. Under normal conditions, convergence increases the basal firing rate of the LPS during primary gaze, resulting in a small degree of eyelid retraction. This may explain why eyelid nystagmus can be evoked by attempted convergence (also known as Pick's sign) (39). 


\section{DECREASED BLINKING}

\section{Overview of Eyelid Closure}

The primary muscle of eyelid closure is the OO, which is innervated by the facial nerve. It originates from multiple bony and connective tissue structures surrounding the medial canthus. The palpebral portion of this muscle-which can be further subdivided into pretarsal and preseptal components-is contained within the upper and lower eyelids and inserts on connective tissue structures surrounding the lateral canthus. The orbital portion of the OO lies outside the eyelids and forms a muscular ellipse encircling the orbit (1). The palpebral and orbital portions of the $\mathrm{OO}$ are innervated by separate populations of motor neurons within the facial nucleus (40). Other muscles of facial expression, such as the corrugator (which draws the eyebrows inferiorly and medially as in frowning), can secondarily contribute to eyelid closure as well (Figure 1).

\section{Supranuclear Control of Spontaneous Blinking}

Normal spontaneous blinking occurs at a rate of 15-20 blinks/ min; this frequency varies considerably between individuals and is somewhat higher in women than men (41). During a blink, the LPS abruptly stops firing, and the palpebral portion (but not the orbital portion) of the OO contracts, resulting in active eyelid closure (in contrast to the passive eyelid depression that occurs during downgaze). As soon as eyelid closure is complete, the OO abruptly stops firing, basal activity of the LPS resumes and

\section{A}

Originating in the riMLF (excitatory)

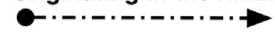
Originating in the M-group (excitatory)

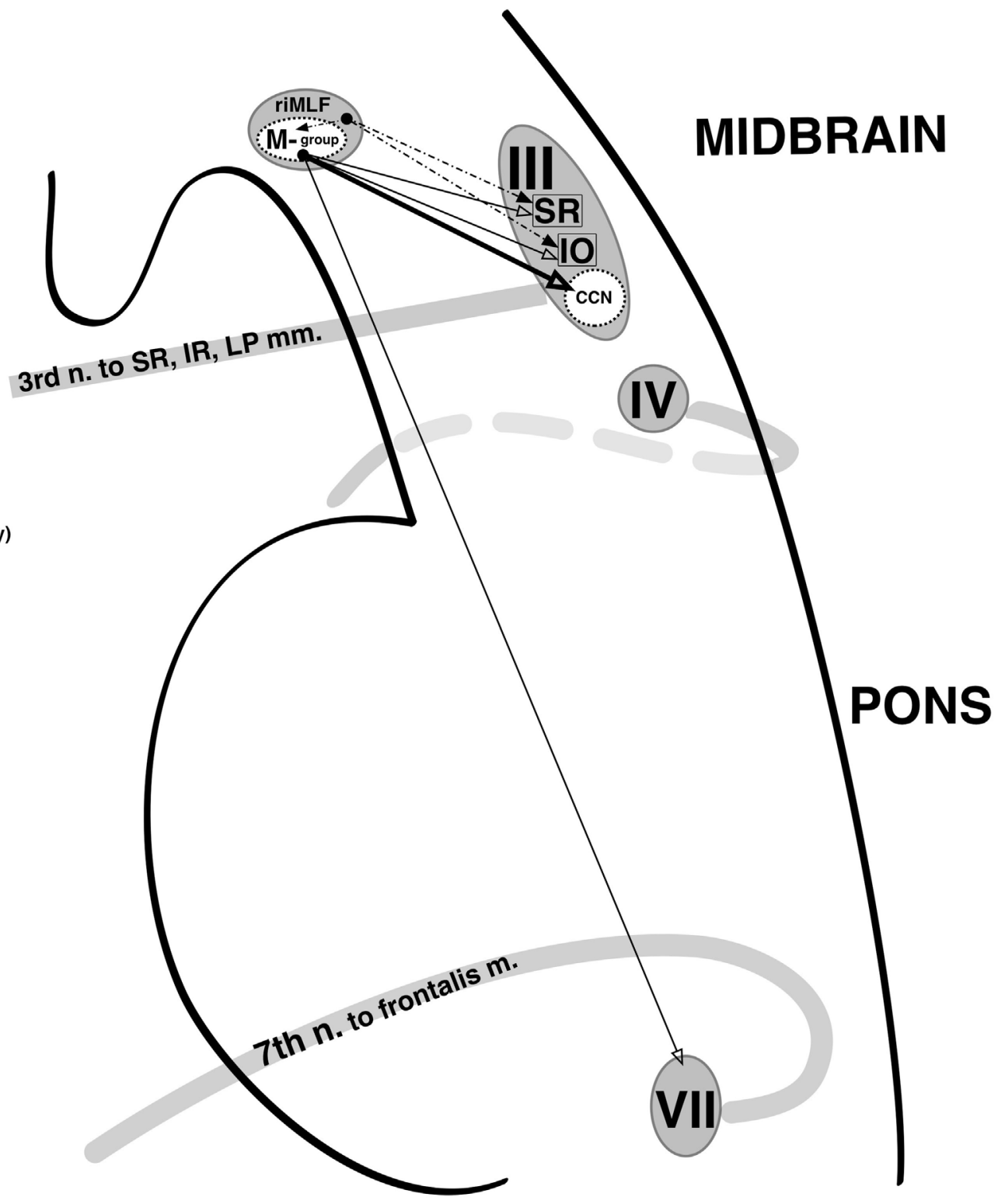




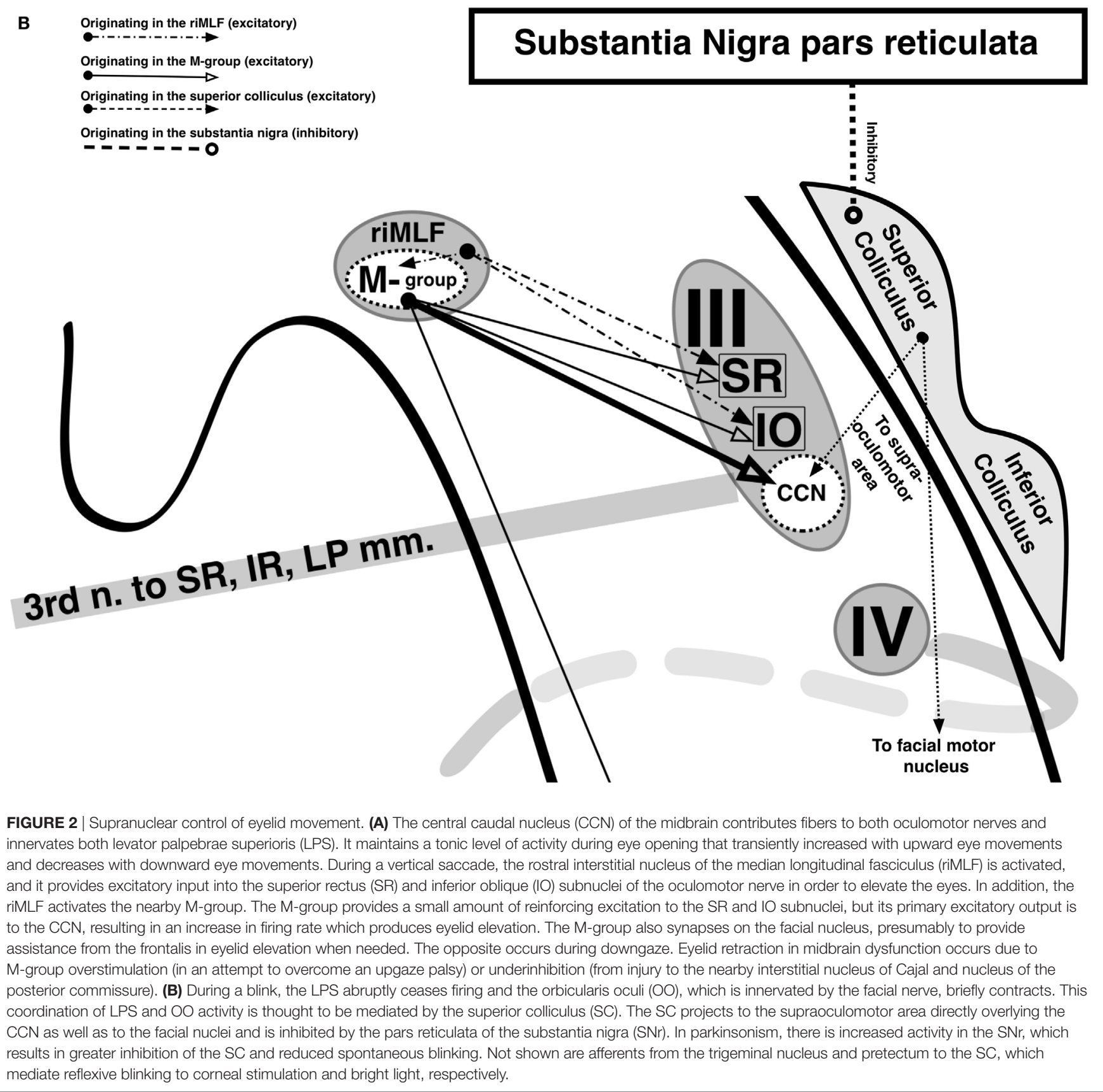

the eyelid opens (42). The duration of eyelid closure in blinking must be very brief to avoid disrupting visual input. Blinking can also occur reflexively in response to various stimuli, including visual threat, bright light, tactile stimulation of the cornea or eyelids, and loud noise. With the exception of visual threat, which involves the occipital cortex, all are mediated by brainstem reflex arcs.

The anatomic pathways through which LPS and OO function is coordinated during blinking remains poorly understood, but the SC is thought to play a key role. The SC sends projections to both the facial motor nucleus and the supraoculomotor area directly overlying the CCN (43). It also receives afferent input from the trigeminal sensory nucleus (important for corneal and other trigeminally mediated blink reflexes) and dorsal midbrain (where reflexive blinking to light is mediated). Inhibitory microstimulation of the SC in primates has been shown to both suppress spontaneous blinking and increase sensitivity to blink reflexes $(44,45)$.

The SC is inhibited by the pars reticulata of the substantia nigra $(\mathrm{SNr})$ through dopaminergic projections in the nigrocollicular pathway. The role of dopamine in promoting spontaneous blinking has been confirmed in animal studies showing an increase in blink rate with apomorphine and other dopamine agonists that 
is abolished in the presence of sulpiride, a dopamine receptor antagonist (46), and a correlation between dopamine level in the caudate nucleus and blink rate in animal models of MPTPinduced parkinsonism (47). Anticholinergics also increase blink rate, consistent with the hypothesis of dopamine-acetylcholine balance in the basal ganglia and the mechanistic rationale for anticholinergics in the treatment of parkinsonism (45).

\section{Reduced Spontaneous Blinking in Parkinsonism}

In $P D$, the spontaneous blink rate has been found to be roughly $30 \%$ lower than healthy controls across several studies $(48,49)$. Blink rate increases with both levodopa therapy (50) and deep brain stimulation (DBS) of the subthalamic nucleus (51). Rarely, PD patients may have an increased spontaneous blink rate that paradoxically decreases to normal with levodopa therapy. Typically seen in cases of advanced disease, this has been postulated by some to represent a type of "off-dystonia" (52). Blink rate is dramatically reduced in PSP to as low as 3 blinks/min, making this a feature that can help distinguish it from PD. Moreover, eyelid movements themselves are of normal amplitude and velocity in PD and are, thus, not technically bradykinetic (53); by contrast, "slow blinks" have been observed in PSP (33).

Since a major function of spontaneous blinking is to evenly distribute the tear film, reduced spontaneous blinking is associated with both subjective and objective complaints of dry eye. In one study, $63 \%$ of PD patients complained of dry eye and related symptoms, and roughly $50 \%$ had objective evidence of xerophthalmia as measured by the Schirmer or tear film build-up time tests (47). Other studies have found a significantly increased prevalence of blepharitis and meibomian gland disease in PD (54). However, these findings are confounded by autonomic dysfunction in PD and may not be solely attributable to decreased blinking and inadequate tear production. Artificial tears are often recommended, but their efficacy has not been specifically studied in this population. A trial of LipiFlow (a pulsating thermal eyepiece) compared to warm compresses for the treatment of meibomian gland dysfunction in PD is currently underway (NCT02894658) (55).

\section{Reflexive Blinking in Parkinsonism}

Given the inverse relationship between spontaneous blinking and blink reflexes, a decrease in dopamine in the SNr would be expected to enhance reflexive blinking. This manifests clinically as the glabellar reflex (trigeminally mediated blinking in response to tapping the nasion or forehead that fails to habituate, also known as Myerson's sign), which is often present in PD (56). However, the glabellar reflex is not unique to $\mathrm{PD}$ and is present in many other structural, metabolic, and degenerative disorders. Reflexive blinking to other stimuli such as bright light is also increased in parkinsonism, particularly in PSP, where a lack of habituation to flashing light has been found to distinguish it from PD (57).

Reflexive blinking can be studied electrophysiologically by stimulating the supraorbital nerve and recording $\mathrm{OO}$ activity using surface or needle electrodes (58). This elicits two responses: $\mathrm{R} 1$, a brief unilateral response that occurs ipsilateral to the side of stimulation with a latency of about $10 \mathrm{~ms}$, and R2, a more sustained bilateral response that occurs with a latency of about $30 \mathrm{~ms}$. When the LPS is recorded, there are two corresponding periods of electromyographic silence (SP1 and SP2) such that LPS and $\mathrm{OO}$ activity never overlap. In addition, repetitive stimulation can be performed to assess reflex excitability. This is based on the concept of prepulse inhibition-that is, through a combination of membrane refractoriness after hyperpolarization and activation of negative feedback circuits, a second stimulus elicits a weaker response compared to the first stimulus. In the case of the blink reflex, R2 is absent when the interstimulus interval is less than $200 \mathrm{~ms}$, reduced by $50-60 \%$ at an interval of $500 \mathrm{~ms}$, and reduced by $10-30 \%$ at an interval of $1,500 \mathrm{~ms}$.

In $\mathrm{PD}$ patients, the $\mathrm{R} 2$ latency is mildly prolonged, consistent with intrinsic brainstem pathology in the early Braak stages of the disease. R2 prolongation has been shown to be greater in $\mathrm{PD}$ patients with dyskinesias compared to those without and in dementia with Lewy bodies compared to PD, both of which are likely a reflection of greater Lewy body burden $(59,60)$. More importantly, the blink reflex is hyperexcitable in PD. In one study, for example, when the supraorbital nerve was stimulated twice over a period of $250 \mathrm{~ms}$, the second R2 was $84 \%$ smaller in amplitude and 50\% shorter in duration compared to the first R2 among healthy controls. By contrast, PD patients off therapy had only a $60 \%$ smaller and $10 \%$ shorter second R2 response (44). Dopaminergic therapy and STN DBS in both humans (61) and animals (62) restores blink reflex excitability to normal levels. The degree of blink reflex hyperexcitability also correlates with severity of bradykinesia, rigidity, gait impairment, dysarthria, and reduced quality of life $(63,64)$.

\section{INCREASED BLINKING AND BLINK- ASSISTED SACCADES}

\section{Spontaneous and Reflexive Blinking in Hyperkinetic Movement Disorders}

If a hypodopaminergic state reduces spontaneous blinking and increases reflexive blinking, then a hyperdopaminergic state would be expected to increase spontaneous blinking and reduce reflexive blinking. This is indeed seen in hyperkinetic movement disorders, such as $H D$. The mean blink rate in HD patients is approximately 36 blinks/min (65), nearly double the normal rate, and up to $75 \%$ of HD patients have subjectively elevated blink rates (66). In one case of juvenile HD, excessive blinking (40 blinks/ min) preceded the development of other disease manifestations by over 2 years (67). Increased spontaneous blinking is the first clinical manifestation of blepharospasm (see below) and has also been described in Wilson's disease (68). Other disorders that are thought to involve a relative excess of dopaminergic transmission and are often treated with dopamine-blocking agents, such as Tourette syndrome (69) and schizophrenia, have increased spontaneous blinking as well. The inverse relationship between spontaneous and reflexive blinking holds true in $\mathrm{HD}$, as the electrophysiologic blink reflex has been shown to be underexcitable compared to normal in both symptomatic (70) and presymptomatic (71) individuals. 


\section{Relationship between Blinking and Saccades}

In normal individuals, spontaneous blinks are inhibited during voluntary saccades, primarily to avoid disrupting visual input during a visually guided task. Saccades are also slower and less accurate when they are interrupted by blinks (72). However, patients with parkinsonian disorders fail to suppress blinks during voluntary saccades. In one study, normal individuals blinked an average of $15.7 / \mathrm{min}$ when fixating in primary gaze and 9.1/ min when asked to alternate looking left and right every $5 \mathrm{~s}$. By contrast, $\mathrm{PD}$ patients experienced a slight increase in blink rate (from 12.5 to $14.8 / \mathrm{min}$ ), and PSP patients a substantial increase in blink rate (from 3.0 to $5.3 / \mathrm{min}$ ) during horizontal eye movements (49). The mechanism underlying this phenomenon is not entirely known, but given that spontaneous blink rates also decrease during mental tasks requiring intense concentration, the frontal lobes are thought to play a role.

While blinks reduce the speed and accuracy of saccades, they can also be used to assist saccades in disorders of saccade initiation (also known as saccadic or ocular motor apraxia). In $\mathrm{HD}$, where difficulty with saccade initiation and prolonged saccadic latency are among the earliest clinical manifestations (73, 74 ), the use of head thrusts and blinks is initially suppressible, but as the disease progresses, patients may be unable to initiate voluntary saccades without an obligatory blink (35\% in one study) (75). Blink-assisted saccades [also termed blink-saccade synkinesis (76)] are observed in other causes of impaired saccade initiation such as the autosomal dominant SCAs, the autosomal recessive ataxias with ocular motor apraxia, ataxia-telangiectasia, congenital ocular motor apraxia, Gaucher disease, NiemannPick disease type C, Joubert syndrome, and others (77). During normal saccade initiation, omnipause neurons in the dorsal pons cease firing, which disinhibits excitatory burst neurons in the parapontine reticular formation (for horizontal saccades) and riMLF (for vertical and torsional saccades), resulting in a saccade. Interestingly, omnipause neuron activity is also suspended during blinks (78). If ocular motor apraxia is caused by a lack of normal supranuclear inhibition of omnipause neurons during saccade initiation, then blink-saccade synkinesis may represent an alternative method of inhibiting omnipause neurons in order to generate saccades.

\section{BLEPHAROSPASM}

\section{Introduction to Blepharospasm}

Blepharospasm is characterized by periods of involuntary, sustained, forceful eyelid closure. As it involves the co-contraction of agonist (OO) and antagonist (LPS) muscles affecting eyelid position, blepharospasm qualifies as a type of focal dystonia, and more than half of patients have a geste antagoniste or sensory trick that can temporarily relieve symptoms (79). It typically presents between the fourth and sixth decades of life and is more common in women than men (80). The initial clinical manifestation of blepharospasm is an increase in spontaneous blink rate that paradoxically decreases with psychomotor activation (81).
Over time, blinks become increasingly forceful and prolonged, involving both the orbital and palpebral portions of the $\mathrm{OO}$ (sometimes termed "dystonic blinks"). Eventually, these blinks coalesce into periods of sustained eyelid closure whose frequency and duration can be so severe as to produce functional blindness (82).

Blepharospasm should not be confused with eyelid myotonia, which is characterized by impaired relaxation following voluntary or reflexive (e.g., sneezing) eyelid closure. Myotonia is seen in myotonic dystrophy as well as the non-dystrophic myotonias (e.g., myotonia congenita, paramyotonia congenita), which are caused by mutations in voltage-gated chloride and sodium channel genes and are treated with sodium channelblocking antiepileptic drugs and the antiarrhythmic drug mexilitene (83).

\section{Pathophysiology of Blepharospasm}

It is postulated that blepharospasm represents overactivity of reflexive blinking, especially to light. Evidence for this theory comes from several observations:

1. Photophobia is an almost universal complaint in blepharospasm (84). Sun exposure has even been postulated to be a risk factor for blepharospasm given that the ratio of blepharospasm to cervical dystonia patients in movement disorders cohorts varies by season and latitude (85). Many patients report that exposure to bright light triggers spasms of eyelid closure and polarized sunglasses can be a useful adjunctive treatment (86). Ocular surface symptoms and sensitivity to tactile stimulation of the cornea and eyelids, which is also a trigger for physiologic reflexive blinking, have also been reported (87).

2. The orbital portion of the $\mathrm{OO}$ is normally involved in reflexive blinking but not spontaneous blinking. Given that the dystonic blinks of blepharospasm involve the orbital portion of the $\mathrm{OO}$, it is suggested that they are generated via reflexive rather than spontaneous blinking pathways.

3. Subclinical overlap in LPS and OO activity is seen at the electromyographic level in normal reflexive blinking to light (88) but not to other stimuli. Thus, the co-contraction of these muscles in blepharospasm may represent an exaggeration of normal reflexive blinking to light.

4. The electrophysiologic blink reflex has been found to be hyperexcitable in patients with blepharospasm $(89,90)$. Interestingly, similar findings have been reported in patients with other focal dystonias besides blepharospasm (e.g., cervical dystonia, spasmodic dysphonia), suggesting shared pathophysiologic mechanisms $(91,92)$. During a geste antagoniste, the R2 duration shortens, but the degree of excitability does not change (93). The use of high-frequency supraorbital nerve stimulation to induce long-term depression of this reflex has been studied as a potential treatment for blepharospasm, albeit with limited success (94).

The site of pathology in blepharospasm remains unknown. The vast majority of patients have normal neuroimaging; in a single case series of 1,114 patients, only $18(1.6 \%)$ had abnormal 
brain MRIs, and lesions localized to a variety of areas, including the basal ganglia, thalami, cerebellum, midbrain, and even cortex (95). Voxel-based morphometric and diffusion-tensor imaging studies have reported changes in the gray matter volume of the caudate, putamen, thalami, and cerebellum, but they have not been consistent (some reported increases, whereas others reported decreases), and it is unclear if they represent the primary site of pathology or adaptive changes in response to disease processes occurring elsewhere (96). Functional neuroimaging studies have shown hypermetabolism of a variety of cortical and deep gray matter foci, both at rest (97) and during tasks such as voluntary blinking (98), and decreased striatal dopamine binding in roughly one-third of patients (99). A case report of craniocervical blepharospasm treated with DBS found increased firing rates in the globus pallidus interna (100).

\section{Epidemiology and Natural History of Blepharospasm}

Blepharospasm may remain limited to the OO or may spread to adjacent muscles of the face, jaw, and neck, resulting in craniocervical dystonia (also known as Meige syndrome). This spread usually occurs within 5 years of blepharospasm onset $(101,102)$. The lifetime risk of generalization to craniocervical dystonia has been reported to be as high as $60 \%$, though the evidence for this comes from cohort studies recruited from tertiary movement disorders centers, where the study population may not be representative of all patients with blepharospasm $(103,104)$. Greater age of onset, female sex, and a prior history of minor head trauma have been identified as risk factors (105). A single nucleotide polymorphism in the $3^{\prime}$ untranslated region of the TOR1A gene, which is the causative gene in DYT1, was also associated with a twofold increase in risk of generalization in two separate cohort studies (106). Up to $12 \%$ of patients with blepharospasm experience spontaneous remission (107). Blepharospasm may also occur in patients with parkinsonian disorders, especially PSP but occasionally multiple systems atrophy (MSA) and rarely PD. The risk of developing PSP in patients who present with blepharospasm has not been established but is likely to be low given the rarity of the condition. However, the prevalence of blepharospasm in patients with PSP is high (anywhere from 20 to $70 \%)(33,108,109)$. Anywhere from 5 to $30 \%(110)$ of patients with blepharospasm also have apraxia of eyelid opening (AEO) (see below); the combination of the two is especially common in PSP. Blepharospasm has also been reported in patients with autosomal dominant SCAs (6) and neurodegeneration with brain iron accumulation (111). It can be the presenting symptom of an inherited generalized dystonia (e.g., DYT1) and may be the only clinical manifestation in families with autosomal dominant focal dystonia.

\section{Treatment of Blepharospasm}

The treatment of choice for blepharospasm is chemodenervation of the $\mathrm{OO}$ with botulinum toxin. In addition to relieving the clinical symptoms of blepharospasm, botulinum toxin lowers the spontaneous blink rate (112) and reduces blink reflex hyperexcitability (113), presumably by reducing corneal sensory input from eye closure. In mild cases that present primarily with photophobia and increased blink frequency, polarized lenses may be useful. Some patients also report symptom improvement by wearing a tight band around the forehead, providing a constant geste antagoniste. Other conservative treatments that have been studied include behavioral therapy to encourage eyelid relaxation, biofeedback using EMG recording of the frontalis muscle (114), and transcranial magnetic stimulation (115). Medications that are typically used to treat other forms of dystonia (e.g., anticholinergics, baclofen, and benzodiazepines, levodopa) have been tried with mixed results. Prior to the advent of botulinum chemodenervation, surgical myectomy was routinely performed but is now reserved for the rare botulinum-resistant or intolerant patient (116). DBS has been performed in a few refractory cases with encouraging results (117).

\section{APRAXIA OF EYELID OPENING AND CLOSURE}

\section{Overview of Voluntary Eyelid Control}

The supranuclear control of voluntary eyelid elevation and depression is complex and poorly understood. Electrical stimulation of a number of frontal, temporal, parietal, and occipital lobar sites can elicit eye opening or closure, and the cortical control of eyelid position is thought to have a right hemispheric predominance (1). The impairment of voluntary eyelid motor control results in difficulty initiating voluntary eye opening and difficulty maintaining eye opening during the normal waking state. This syndrome was first described by Goldstein and Cogan in 1965, who called it "apraxia of lid opening" (118), though the use of the term apraxia has since been criticized, and other names, such as blepharocolysis, akinesia of lid opening and function, eyelid freezing, and involuntary levator palpebrae inhibition of supranuclear origin, have been proposed. Clinically, AEO consists of difficulty initiating eyelid elevation following sustained voluntary eyelid closure without evidence of involuntary $\mathrm{OO}$ activity. Electrophysiologically, it is characterized by the absence of LPS activity during attempted eyelid opening without concurrent palpebral or orbital $\mathrm{OO}$ activity as would be seen in light or forced voluntary eyelid closure, respectively. The frontalis muscle is often tonically activated in an attempt to secondarily elevate the upper eyelids. Spontaneous blinking and reflexive blinking are clinically and electrophysiologically normal, confirming that the neuromuscular apparatus of the levator palpebrae is intact and that the disorder is one of supranuclear control. PET studies have demonstrated medial frontal hypometabolism in the anterior cingulate and supplemental motor areas $(119,120)$.

There is evidence to suggest that at least a subset of patients with AEO may have a form of dystonia. As many as one-third of patients with AEO report a geste antagoniste, typically a light touch of the eyelids, that allows for temporary eye opening (121). Blepharospasm may co-exist, and AEO is occasionally unmasked by chemodenervation of the $\mathrm{OO}$ to treat blepharospasm, mistaken as treatment failure or ptosis due to the spread of botulinum toxin and treated with the addition of botulinum toxin to the pretarsal OO (122-124). While the OO is by definition clinically and 
electrophysiologically silent in AEO, selective electromyographic recordings of the pretarsal portion of the OO have revealed the presence of abnormal activity in some patients (125). Because of its technical challenges, this finding has been difficult to replicate on a larger scale, and it is unclear if these patients truly have AEO, a subtle variant of blepharospasm, or a distinct entity altogether that some have termed "OO motor persistence."

\section{Neurodegenerative Diseases Associated With AEO}

Apraxia of eyelid opening may occur in isolation or in association with an underlying neurodegenerative disorder. Of 32 patients with AEO seen at a regional referral center in Puglia, Italy, over a 10 -year period, 10 were healthy, 10 had blepharospasm, 6 had PSP, and 3 had idiopathic PD (126). The number of patients with AEO who have PD may be similar to the number of patients who have PSP, but because PSP is so much rarer than idiopathic PD, the prevalence of AEO is much higher in PSP. Anywhere from 30 to $45 \%$ of patients with PSP experience AEO (127). Furthermore, AEO typically coincides with or precedes the onset of parkinsonism in PSP, whereas it is a much later manifestation of PD. AEO is also seen in MSA and corticobasal syndrome, though in the latter the underlying pathology at autopsy is one of PSP rather than true corticobasal ganglionic degeneration (128). It has also been described in cases of amyotrophic lateral sclerosis (ALS) with or without frontotemporal disease, HD, SCA2 (129), SCA3 (130), Wilson's disease, chorea-acanthocytosis, and others.

A benign unilateral AEO has been described which typically occurs on awakening and resolves after manual elevation of the affected eyelid (131). While this could represent a geste antagoniste, EMG studies are lacking due to the transient nature of these symptoms, and it is unclear whether this condition reflects excess OO activation or excess LPS inhibition (132). Apraxia of eyelid closure has also been described but is much less common. These patients constrict the corrugator and procerus muscles during attempted voluntary eyelid closure but not the OO (133); however, they are able to close their eyes normally during spontaneous and reflexive blinking. It has been reported in patients with PSP (33), HD (134), Creutzfeldt-Jakob disease, ALS (135), and acquired frontal and parietal lobe disease.

\section{REFERENCES}

1. Liu GT, Volpe NJ, Galetta SL. Neuro-Ophthalmology: Diagnosis and Management. 2nd ed. Philadelphia, PA: Elsevier (2010).

2. Porter JD, Burns LA, May PJ. Morphological substrate for eyelid movements: innervation and structure of primary levator palpebrae superioris and orbicularis oculi muscles. J Comp Neurol (1989) 287(1):64-81. doi:10.1002/ cne.902870106

3. McClelland C, Manousakis G, Lee MS. Progressive external ophthalmoplegia. Curr Neurol Neurosci Rep (2016) 16(6):53. doi:10.1007/s11910-0160652-7

4. Milone M, Wong LJ. Diagnosis of mitochondrial myopathies. Mol Genet Metab (2013) 110(1-2):35-41. doi:10.1016/j.ymgme.2013.07.007

5. Taylor RW, Turnbull DM. Mitochondrial DNA mutations in human disease. Nat Rev Genet (2005) 6(5):389-402. doi:10.1038/nrg1606

6. Paulson HL. The spinocerebellar ataxias. J Neuroophthalmol (2009) 29(3):227-37. doi:10.1097/WNO0b013e3181b416de

\section{Treatment of AEO}

The treatment of AEO requires a multimodal approach. Conservative measures include wearing goggles (136) or eyelid crutches (137); these serve to mechanically elevate the upper eyelid but likely also act as a geste antagoniste. Levodopa may improve AEO when it is isolated (138) or associated with PD $(139,140)$ but appears to worsen it when associated with PSP. Other medications that have been tried on a case-by-case basis include anticholinergics (141), atypical antipsychotics (142), and methylphenidate (143). Given the finding of abnormal EMG activity in the pretarsal OO in some patients with AEO, botulinum injection of the pretarsal $\mathrm{OO}$ is frequently performed with success (144). In cases of comorbid blepharospasm and AEO, surgical myectomy (145) or frontalis suspension $(146,147)$ can treat both disorders simultaneously but are generally reserved as a last resort.

The association between AEO and PD deserves special attention as it can be confounded by DBS (148). While AEO may be present in untreated PD, it can emerge or worsen after STN DBS (or posteroventral pallidotomy during the pre-DBS era) in anywhere from 2 to $31 \%$ of patients, presumably via the spread of current into the adjacent corticobulbar tract, particularly when higher voltages are applied to more caudal contact points. In fact, experimental low-frequency stimulation of the STN at certain voltage thresholds has been shown to induce myoclonus in the pretarsal OO (149). The weaning of levodopa following DBS may also unmask pre-existing symptoms (150). AEO usually occurs within a year of DBS implantation. An increase in spontaneous blink rate can be a harbinger of AEO during programming sessions (151). Treatment is challenging and consists of reducing voltage, increasing frequency, and administering levodopa in addition to conventional therapies. Paradoxically, some patients with AEO experience improvement with STN $(151,152)$ or GPi (153) DBS.

\section{AUTHOR CONTRIBUTIONS}

AH performed the primary literature review and drafted the manuscript. DG conceived of the manuscript idea and edited the manuscript.

7. Zuhlke C, Mikat B, Timmann D, Wieczorek D, Gillessen-Kaesbach G, Burk K. Spinocerebellar ataxia 28: novel AFG3L2 mutation in a German family with young onset, slow progression and saccadic slowing. Cerebellum Ataxias (2015) 2:19. doi:10.1186/s40673-015-0038-7

8. Gorman GS, Pfeffer G, Griffin H, Blakely EL, Kurzawa-Akanbi M, Gabriel J, et al. Clonal expansion of secondary mitochondrial DNA deletions associated with spinocerebellar ataxia type 28. JAMA Neurol (2015) 72(1):106-11. doi:10.1001/jamaneurol.2014.1753

9. Kiferle L, Orsucci D, Mancuso M, Lo Gerfo A, Petrozzi L, Siciliano G, et al. Twinkle mutation in an Italian family with external progressive ophthalmoplegia and parkinsonism: a case report and an update on the state of the art. Neurosci Lett (2013) 556:1-4. doi:10.1016/j.neulet.2013. 09.034

10. Amboni M, Pellecchia MT, Cozzolino A, Picillo M, Vitale C, Barone P, et al. Cerebellar and pyramidal dysfunctions, palpebral ptosis and weakness as the presenting symptoms of PARK-2. Mov Disord (2009) 24(2):303-5. doi:10.1002/mds. 22342 
11. Wong KT, Dick D, Anderson JR. Mitochondrial abnormalities in oculopharyngeal muscular dystrophy. Neuromuscul Disord (1996) 6(3):163-6. doi:10.1016/0960-8966(95)00039-9

12. Yum K, Wang ET, Kalsotra A. Myotonic dystrophy: disease repeat range, penetrance, age of onset, and relationship between repeat size and phenotypes. Curr Opin Genet Dev (2017) 44:30-7. doi:10.1016/j.gde.2017.01.007

13. Poulton J, Harley HG, Dasmahapatra J, Brown GK, Potter CG, Sykes B. Mitochondrial DNA does not appear to influence the congenital onset type of myotonic dystrophy. J Med Genet (1995) 32(9):732-5. doi:10.1136/ jmg.32.9.732

14. Engel AG, Shen XM, Selcen D, Sine SM. Congenital myasthenic syndromes: pathogenesis, diagnosis, and treatment. Lancet Neurol (2015) 14(4):420-34. doi:10.1016/S1474-4422(14)70201-7

15. SooHoo JR, Davies BW, Allard FD, Durairaj VD. Congenital ptosis. Surv Ophthalmol (2014) 59:483-92. doi:10.1016/j.survophthal.2014.01.005

16. Pavone P, Barbagallo M, Parano E, Pavone L, Souayah N, Trifiletti RR. Clinical heterogeneity in familial congenital ptosis: analysis of fourteen cases in one family over five generations. Pediatr Neurol (2005) 33:251-4. doi:10.1016/ j.pediatrneurol.2005.03.018

17. Clark BJ, Kemp EG, Behan WM, Lee WR. Abnormal extracellular material in the levator palpebrae superioris complex in congenital ptosis. Arch Ophthalmol (1995) 113:1414-9. doi:10.1001/archopht.1995.01100110074028

18. Mendes S, Beselga D, Campos S, Neves A, Campos J, Carvalho S, et al. Possible rare congenital dysinnervation disorder: congenital ptosis associated with adduction. Strabismus (2015) 23(1):33-5. doi:10.3109/09273972. 2014.999797

19. Heidary G, Engle EC, Hunter DG. Congenital fibrosis of the extraocular muscles. Semin Ophthalmol (2008) 23(1):3-8. doi:10.1080/08820530701745181

20. Yuksel D, Orban de Xivry JJ, Lefevre P. Review of the major findings about Duane retraction syndrome (DRS) leading to an updated form of classification. Vision Res (2010) 50(23):2334-47. doi:10.1016/j.visres.2010. 08.019

21. Kersten RC, de Conciliis C, Kulwin DR. Acquired ptosis in the young and middle-aged adult population. Ophthalmology (1995) 102:924-8. doi:10.1016/S0161-6420(95)30933-5

22. Verhulst S, Smet H, De Wilde F, Tassignon MJ. Levator aponeurosis dehiscence in a patient treated with botulinum toxin for blepharospasms and eyelid apraxia. Bull Soc Belge Ophthalmol (1994) 252:51-3.

23. Allen RC. Genetic diseases affecting the eyelids: what should a clinician know? Curr Opin Ophthalmol (2013) 24:463-77. doi:10.1097/ ICU.0b013e3283638219

24. Ng J, Papandreou A, Jeales SJ, Kurian MA. Monoamine neurotransmitter disorders - clinical advances and future directions. Nat Rev Neurol (2015) 11:567-84. doi:10.1038/nrneurol.2015.172

25. Becker W, Fuchs AF. Lid-eye coordination during vertical gaze changes in man and monkey. J Neurophysiol (1988) 60:1227-52.

26. Rucker JC. Normal and abnormal lid function. Handb Clin Neurol (2011) 102(3):403-24. doi:10.1016/B978-0-444-52903-9.00021-2

27. Fuchs AF, Becker W, Ling L, Langer TP, Kaneko CR. Discharge patterns of levator palpebrae superioris motoneurons during vertical lid and eye movements in the monkey. J Neurophysiol (1992) 68(1):233-43.

28. Evinger C, Shaw MD, Peck CK, Manning KA, Baker R. Blinking and associated eye movements in humans, guinea pigs, and rabbits. J Neurophysiol (1984) 52(2):323-39.

29. Robinson DA. Oculomotor unit behavior in the monkey. J Neurophysiol (1970) 33(3):393-403.

30. Horn AK, Buttner-Ennever JA, Gayde M, Messoudi A. Neuroanatomical identification of mesencephalic premotor neurons coordinating eyelid with Upgaze in the Monkeyand Man.J CompNeurol(2000)420:19-34.doi:10.1002/ (SICI)1096-9861(20000424)420:1<19::AID-CNE2>3.0.CO;2-D

31. Horn AK, Buttner-Ennever JA. Brainstem circuits controlling lid-eye coordination in monkeys. Prog Brain Res (2008) 171:87-95. doi:10.1016/ S0079-6123(08)00612-2

32. Keane JR. The pretectal syndrome: 206 patients. Neurology (1990) 40:684-90. doi:10.1212/WNL.40.4.684

33. Friedman DI, Jankovic J, McCrary JA. Neuro-ophthalmic findings in progressive supranuclear palsy. J Clin Neuroophthalmol (1992) 12(2):104-9.
34. Onofrj M, Monaco D, Bonani L, Onofrj V, Bifolchetti S, Manzoli L, et al. Eyelid retraction in dementia with Lewy bodies and Parkinson's disease. J Neurol (2011) 258(8):1542-4. doi:10.1007/s00415-011-5942-Z

35. Moro A, Munhoz RP, Arruda WO, Raskin S, Teive HA. Clinical relevance of "bulging eyes" for the differential diagnosis of spinocerebellar ataxias. Arq Neuropsiquiatr (2013) 71(7):428-30. doi:10.1590/0004-282X20130056

36. Milivojevic I, Bakran Z, Adamec I, Miletic Grskovic S, Habek M. Eyelid nystagmus and primary position upbeat nystagmus. Neurol Sci (2013) 34(8):1463-4. doi:10.1007/s10072-012-1211-x

37. Howard RS. A case of convergence evoked eyelid nystagmus. JClin Neuroophthal (1986) 6(3):169-71.

38. Safran AB, Berney J, Safran E. Convergence-evoked eyelid nystagmus. Am J Ophthalmol (1982) 93(1):48-51.

39. Sanders MD, Hoyt WF, Daroff RB. Lid nystagmus evoked by ocular convergence: an ocular electromyographic study. J Neurol Neurosurg Psychiatry (1968) 31(4):368-71.

40. VanderWerf F, Brassinga P, Reits D, Aramideh M, Ongerboer de Visser B. Eyelid movements: behavioral studies of blinking in humans under different stimulus conditions. J Neurophysiol (2003) 89:2784-96. doi:10.1152/ jn.00557.2002

41. Sforza C, Rango M, Galante D, Bresolin N, Ferrario VF. Spontaneous blinking in healthy persons: an optoelectric study of eyelid motion. Ophthalmic Physiol Opt (2008) 28(4):345-53. doi:10.1111/j.1475-1313.2008.00577.x

42. Esteban A, Salinero E. Reciprocal reflex activity in ocular muscles: implications in spontaneous blinking and Bell's phenomenon. Eur Neurol (1979) 18:157-65. doi:10.1159/000115072

43. Schmidtke N, Buttner-Ennever JA. Nervous control of eyelid function: a review of clinical, experimental, and pathological data. Brain (1992) 115:227-47. doi:10.1093/brain/115.1.227

44. Gnadt JW, Lu SM, Breznen B, Basso MA, Henriquez VM, Evinger C. Influence of the superior colliculus on the primate blink reflex. Exp Brain Res (1997) 116:389-98. doi:10.1007/PL00005767

45. Basso MA, Powers AS, Evinger C. An explanation for reflex blink hyperexcitability in Parkinson's disease. I. Superior colliculus. J Neurosci (1996) 16(22):7308-17.

46. Karson CN. Spontaneous eye-blink rates and dopaminergic systems. Brain (1983) 106:643-53. doi:10.1093/brain/106.3.643

47. Taylor JR, Elsworth JD, Lawrence MS, Sladek JR Jr, Roth RH, Redmond DE Jr. Spontaneous blink rates correlate with dopamine levels in the caudate nucleus of MPTP-treated monkeys. Exp Neurol (1999) 158(1):214-20. doi:10.1006/exnr.1999.7093

48. Biousse V, Skibell BC, Watts RL, Loupe DN, Drews-Botsch C, Newman NJ. Ophthalmologic features of Parkinson's disease. Neurology (2004) 62(2):177-80. doi:10.1212/01.WNL.0000103444.45882.D8

49. Golbe LI, Davis PH, Lepore FE. Eyelid movement abnormalities in progressive supranuclear palsy. Mov Disord (1989) 4(4):297-302. doi:10.1002/ mds.870040402

50. Agostino R, Bologna M, Dinapoli L, Gregori B, Fabbrini G, Accornero N, et al. Voluntary spontaneous, and reflex blinking in Parkinson's disease. Mov Disorder (2008) 23(5):669-75. doi:10.1002/mds.21887

51. Bologna M, Fasano A, Modugno N, Fabbrini G, Berardelli A. Effects of subthalamic nucleus deep brain stimulation and L-DOPA on blinking in Parkinson's disease. Exp Neurol (2012) 235(1):265-72. doi:10.1016/ j.expneurol.2012.02.004

52. Kimber TE, Thompson PD. Increased blink rate in advanced Parkinson's disease: a form of 'off'-period dystonia? Mov Disord (2000) 15(5): 982-5. doi:10.1002/1531-8257(200009)15:5<982::AID-MDS1033>3.0.CO; 2-P

53. Korosec M, Zidar I, Reits D, Evinger C, Vanderwerf F. Eyelid movements during blinking in patients with Parkinson's disease. Mov Disord (2006) 21(8):1248-51. doi:10.1002/mds.20930

54. Nowacka B, Lubinski W, Honczarenko K, Potemkowski A, Safranow K. Ophthalmological features of Parkinson's disease. Ophthalmological features of Parkinson's disease. Med Sci Monit (2014) 20:2243-9. doi:10.12659/ MSM.890861

55. Burden S. Lipiflow Versus Warm Compresses in Parkinson's Disease (2016). Available from: https://clinicaltrials.gov/ct2/show/NCT02894658?term= lipiflow\&rank=4 
56. Brodsky H, Dat Vuong K, Thomas M, Jankovic J. Glabellar and palmomental reflexes in parkinsonian disorders. Neurology (2004) 63(6):1096-8. doi:10.1212/01.WNL.0000140249.97312.76

57. KuniyoshiS, Riley DE, Zee DS, Reich SG, Whitney C, Leigh RJ. Distinguishing progressive supranuclear palsy from other forms of Parkinson's disease: evaluation of new signs. Ann N Y Acad Sci (2002) 956:484-6. doi:10.111 1/j.1749-6632.2002.tb02862.x

58. Aramideh M, Ongerboer de Visser BW. Brainstem reflexes: electrodiagnostic techniques, physiology, normative data, and clinical applications. Muscle Nerve (2002) 26(1):14-30. doi:10.1002/mus.10120

59. Iriarte LM, Chacon J, Madrazo J, Chaparro P, Vadillo J. Blink reflex in dyskinetic and nondyskinetic patients with Parkinson's disease. Eur Neurol (1989) 29(2):67-70. doi:10.1159/000116380

60. Bonanni L, Anzellotti F, Varanese S, Thomas A, Manzoli L, Onofrj M. Delayed blink reflex in dementia with Lewy bodies. J Neurol Neurosurg Psychiatry (2007) 78(10):1137-9. doi:10.1136/jnnp.2006.113746

61. Costa J, Valls-Sole J, Valldeoriola F, Pech C, Rumia J. Single subthalamic nucleus deep brain stimuli inhibit the blink reflex in Parkinson's disease patients. Brain (2006) 129:1758-67. doi:10.1093/brain/awl143

62. Kaminer J, Thakur P, Evinger C. Effects of subthalamic deep brain stimulation on blink abnormalities of 6-OHDA lesioned rats. JNeurophysiol (2015) 1113(9):3038-46. doi:10.1152/jn.01072.2014

63. Iriarte LM, Chacon J, Madrazo J, Chaparro P, Vadillo J. Blink reflex in 57 parkinsonian patients with correlation between the clinical and electrophysiological parameters. Funct Neurol (1988) 3(2):147-56.

64. Matsumoto H, Noro H, Kaneshige Y, Chiba S, Miyano N, Motoi Y, et al. A correlation study between blink reflex habituation and clinical state in patients with Parkinson's disease. JNeurol Sci (1992) 107(2):155-9. doi:10.1016/0022-510X(92)90283-Q

65. Karson CN, Burns RS, LeWitt PA, Foster NL, Newman RP. Blink rates and disorders of movement. Neurology (1984) 34(5):677-8. doi:10.1212/ WNL.34.5.677

66. Fekete R, Jankovic J. Upper facial chorea in Huntington disease. J Clin Mov Disord (2014) 1:7. doi:10.1186/2054-7072-1-7

67. Xing S, Chen L, Chen X, Pei Z, Zeng J, Li J. Excessive blinking as an initial manifestation of juvenile Huntington's disease. Neurol Sci (2008) 29(4):275-7. doi:10.1007/s10072-008-0981-7

68. Verma R, Lalla R, Patil TB. Is blinking of the eyes affected in extrapyramidal disorders? An interesting observation in a patient with Wilson disease. BMJ Case Rep (2012) 2012. doi:10.1136/bcr-2012-007367

69. Tharp JA, Wendelken C, Mathews CA, Marco EJ, Schreier H, Bunge SA. Tourette syndrome: complementary insights from measures of cognitive control, eyeblink rate, and pupil diameter. Front Psychiatry (2015) 6:95. doi:10.3389/fpsyt.2015.00095

70. Esteban A, Gimenez-Roldan S. Blink reflex in Huntington's chorea and Parkinson's disease. Acta Neurol Scand (1975) 52(2):145-57. doi:10.111 1/j.1600-0404.1975.tb05768.x

71. De Tommaso M, Sciruicchio V, Spinelli A, Specchio N, Difruscolo O, Puca F, et al. Features of the blink reflex in individuals at risk for Huntington's disease. Muscle Nerve (2001) 24(11):1520-5. doi:10.1002/mus.1177

72. Rottach KG, Das VE, Wohlgemuth W, Zivotofsky AZ, Leigh RJ. Properties of horizontal saccades accompanied by blinks. JNeurophysiol (1998) 79(6):2895-902.

73. Lasker AG, Zee DS. Ocular motor abnormalities in Huntington's disease. Vision Res (1997) 37:3639-45. doi:10.1016/S0042-6989(96)00169-1

74. Golding CV, Danchaivijitr C, Hodgson TL, Tabrizi SJ, Kennard C. Identification of an oculomotor biomarker of preclinical Huntington disease. Neurology (2006) 67:485-7. doi:10.1212/01.wnl.0000218215.43328.88

75. Leigh RJ, Newman SA, Folstein SE, Lasker AG, Jensen BA. Abnormal ocular motor control in Huntington's disease. Neurology (19831) 33(10):1268-75. doi:10.1212/WNL.33.10.1268

76. Zee DS, Chu FC, Leigh RJ, Savino PJ, Schatz NJ, Reingold DB, et al. Blink-saccade dynkinesis. Neurology (1983) 33(9):1233-6. doi:10.1212/ WNL.33.9.1233

77. Cogan DG, Chu FC, Reingold D, Barranger J. Ocular motor signs in some metabolic diseases. Arch Ophthalmol (1981) 99(10):1802-8. doi:10.1001/ archopht.1981.03930020676010
78. Schultz KP, Williams CR, Busettini C. Macaque pontine omnipause neurons play no direct role in the generation of eye blinks. J Neurophysiol (2010) 103(4):2255-74. doi:10.1152/jn.01150.2009

79. Martino D, Liuzzi D, Macerollo A, Aniello MS, Livrea P, Defazio G. The phenomenology of the geste antagoniste in primary blepharospasm and cervical dystonia. Mov Disord (2010) 25(4):407-12. doi:10.1002/mds.23011

80. Steeves TD, Day L, Dykeman J, Jette N, Pringsheim T. The prevalence of primary dystonia: a systematic review and meta-analysis. Mov Disord (2012) 27(14):1789-96. doi:10.1002/mds.25244

81. Bentivoglio AR, Daniele A, Albanese A, Tonali PA, Fasano A. Analysis of blink rate in patients with blepharospasm. Mov Disord (2006) 21(8):1225-9. doi:10.1002/mds.20889

82. Valls-Sole J, Defazio G. Blepharospasm: update on epidemiology, clinical aspects, and pathophysiology. Front Neurol (2016) 7:45. doi:10.3389/ fneur.2016.00045

83. Matthews E, Fialho D, Tan SV, Venance SL, Cannon SC, Sternberg D, et al. The non-dystrophic myotonias: molecular pathogenesis, diagnosis, and treatment. Brain (2010) 133(1):9-22. doi:10.1093/brain/awp294

84. Katz BJ, Digre KB. Diagnosis, pathophysiology, and treatment of photophobia. Surv Ophthalmol (2016) 61(4):466-77. doi:10.1016/j. survophthal.2016.02.001

85. Molloy A, Williams L, Kimmich O, Butler JS, Beiser I, McGovern E, et al. Sun exposure is an environmental risk factor for the development of blepharospasm. J Neurol Neurosurg Psychiatry (2016) 87(4):420-4. doi:10.1136/ jnnp-2014-310266

86. Blackburn MK, Lamb RD, Digre KB, Smith AG, Warner JE, McClane RW, et al. FL-41 tint improves blink frequency, light sensitivity, and functional limitations in patients with benign essential blepharospasm. Ophthalmology (2009) 116(5):997-1001. doi:10.1016/j.ophtha.2008.12.031

87. Martino D, Defazio G, Alessio G, Abbruzzese G, Girlanda P, Tinazzi M, et al. Relationship between eye symptoms and blepharospasm: a multicenter case-control study. Mov Disord (2005) 20:1564-70. doi:10.1002/mds.20635

88. Manning KA, Evinger C. Different forms of blinks and their two-stage control. Exp Brain Res (1986) 64(3):579-88. doi:10.1007/BF00340495

89. Tisch S, Limousin P, Rothwell JC, Asselman P, Quinn N, Jahanshahi M, et al. Changes in blink reflex excitability after globus pallidus internus stimulation for dystonia. Mov Disord (2006) 21(10):1650-5. doi:10.1002/mds.20899

90. Schwingenschuh P, Katschnig P, Edwards MJ, Teo JT, Korlipara LV, Rothwell JC, et al. The blink reflex recovery cycle differs between essential and presumed psychogenic blepharospasm. Neurology (2011) 76(7):610-4. doi:10.1212/WNL.0b013e31820c3074

91. Tolosa E, Montserrat L, Bayes A. Blink reflex studies in patients with focal dystonias. Adv Neurol (1988) 50:517-24.

92. Cohen LG, Ludlow CL, Warden M, Estegui M, Agostino R, Sedory SE, et al. Blink reflex excitability recovery curves in patients with spasmodic dysphonia. Neurology (1989) 39(4):572-7. doi:10.1212/WNL.39.4.572

93. Gómez-Wong E, Martí MJ, Cossu G, Fabregat N, Tolosa ES, Valls-Solé J. The 'geste antagonistique' induces transient modulation of the blink reflex in human patients with blepharospasm. Neurosci Lett (1998) 251(2):125-8. doi:10.1016/S0304-3940(98)00519-9

94. Kranz G, Shamim EA, Lin PT, Kranz GS, Hallet M. Long term depression-like plasticity of the blink reflex for the treatment of blepharospasm. Mov Disord (2013) 28(4):498-503. doi:10.1002/mds.25329

95. Khooshnoodi MA, Factor SA, Jinnah HA. Secondary blepharospasm associated with structural lesions of the brain. J Neurol Sci (2013) 331(102):98-101. doi:10.1016/j.jns.2013.05.022

96. Hallett M, Evinger C, Jankovic J, Stacy M; BEBRF International Workshop. Update on blepharospasm: report from the BEBRF international workshop. Neurology (2008) 71:1275-82. doi:10.1212/01.wnl.0000327601.46315.85

97. Zhou B, Wang J, Huang Y, Yang Y, Gong Q, Zhou D. A resting state functional magnetic resonance imaging study of patients with benign essential blepharospasm. J Neuroophthalmol (2013) 33(3):235-40. doi:10.1097/ WNO.0b013e31828f69e5

98. Baker RS, Andersen AH, Morecraft RJ, Smith CD. A functional magnetic resonance imaging study in patients with benign essential blepharospasm. JNeuroophthalmol (2003) 23(1):11-5. doi:10.1097/00041327-200303000-00003 
99. Horie C, Suzuki Y, Kiyosawa M, Mochizuki M, Wakakura M, Oda $\mathrm{K}$, et al. Decreased dopamine $\mathrm{D}$ receptor binding in essential blepharospasm. Acta Neurol Scand (2009) 119(1):49-54. doi:10.1111/j.1600-0404.2008.01053.x

100. Foote KD, Sanchez JC, Okun MS. Staged deep brain stimulation for refractory craniofacial dystonia with blepharospasm: case report and physiology. Neurosurgery (2005) 56:E415. doi:10.1227/01.NEU.0000147978.67424.42

101. Abbruzzese G, Berardelli A, Girlanda P, Marchese R, Martino D, Morgante F, et al. Long-term assessment of the risk of spread in primary late-onset focal dystonia. J Neurol Neurosurg Psychiatry (2008) 79:392-6. doi:10.1136/ jnnp.2007.124594

102. Svetel M, Pekmezovic T, Tomic A, Kresojevic N, Kostic VS. The spread of primary late-onset focal dystonia in a long-term follow up study. Clin Neurol Neurosurg (2015) 132:41-3. doi:10.1016/j.clineuro.2015.02.015

103. Martino D, Berardelli A, Abbruzzese G, Bentivoglio AR, Esposito M, Fabbrini $\mathrm{G}$, et al. Age at onset and symptom spread in primary focal dystonia. Mov Disord (2012) 27(11):1447-50. doi:10.1002/mds.25088

104. Weiss EM, Hershey T, Karimi M, Racette B, Tabbal SD, Mink JW, et al. Relative risk of spread of symptoms among the focal onset dystonias. Mov Disord (2006) 21(8):1175-81. doi:10.1002/mds.20919

105. Defazio G, Livrea P. Epidemiology of primary blepharosmasm. Mov Disord (2002) 17(1):7-12. doi:10.1002/mds.1275

106. Defazio G, Matarin M, Peckham EL, Martino D, Valente EM, Singleton A, et al. The TOR1A polymorphism rs1182 and the risk of spread in primary blepharospasm. Mov Disord (2009) 24(4):613-6. doi:10.1002/mds.22471

107. Grandas F, Traba A, Alonso F, Esteban A. Blink reflex recovery cycle in patients with blepharospasm unilaterally treated with botulinum toxin. Clin Neuropharmacol (1998) 21(5):307-11.

108. Yoon WT, Chung EJ, Lee SH, Kim BJ, Lee WY. Clinical analysis of blepharospasm and apraxia of eyelid opening in patients with parkinsonism. J Clin Neurol (2005) 1(2):159-65. doi:10.3988/jcn.2005.1.2.159

109. Barclay CL, Lang AE. Dystonia in progressive supranuclear palsy. J Neurol Neurosurg Psychiatry (1997) 62(4):352-6.

110. Defazio G, Livrea P, De Salvia R, Manobianca G, Coviello V, Anaclerio $\mathrm{D}$, et al. Prevalence of primary blepharospasm in a community of Puglia region, Southern Italy. Neurology (2001) 56(11):1579-81. doi:10.1212/ WNL.56.11.1579

111. Egan RA, Weleber RG, Hogarth P, Gregory A, Coryell J, Westaway SK, et al. Neuro-ophthalmologic and electroretinographic findings in pantothenate kinase-associated neurodegeneration (formerly Hallervorden-Spatz disease). Am J Ophthalmol (2005) 140(2):267-74. doi:10.1016/j.ajo.2005.03.024

112. Conte A, Berardelli I, Ferrazzano G, Pasquini M, Berardelli A, Fabbrini G. Non-motor symptoms in patients with adult-onset focal dystonia: sensory and psychiatric disturbances. Parkinsonism Relat Disord (2016) 22:S111-4. doi:10.1016/j.parkreldis.2015.09.001

113. Quartarone A, Sant'Angelo A, Battaglia F, Bagnato S, Rizzo V, Morgante F, et al. Enhanced long-term potentiation-like plasticity of the trigeminal blink reflex circuit in blepharospasm. J Neurosci (2006) 26(2):716-21. doi:10.1523/ JNEUROSCI.3948-05.2006

114. Surwit RS, Rotberg M. Biofeedback therapy of essential blepharospasm. Am J Ophthalmol (1984) 98(1):28-31. doi:10.1016/0002-9394(84)90184-3

115. Kranz G, SHamim EA, Lin PT, Kranz GS, Hallett M. Transcranial magnetic brain stimulation modulates blepharospasm: a randomized controlled study. Neurology (2010) 75(16):1465-71. doi:10.1212/WNL.0b013e3181f8814d

116. Pariseau B, Worley MW, Anderson RL. Myectomy for blepharospasm. Curr Opin Ophthalmol (2013) 24(5):488-93. doi:10.1097/ICU. 0b013e3283645aee

117. Yamada K, Shinojima N, Hamasaki T, Kuratsu J. Pallidal stimulation for medically intractable blepharospasm. BMJ Case Rep (2016) 2016. doi:10.1136/ bcr-2015-214241

118. Goldstein JE, Cogan DG. Apraxia of lid opening. Arch Ophthalmol (1965) 73:155-9. doi:10.1001/archopht.1965.00970030157003

119. Smith D, Ishikawa T, Dhawan V, Winterkorn JS, Eidelberg D. Lid-opening apraxia is associated with medial frontal hypometabolism. Mov Disord (1995) 10(3):341-4. doi:10.1002/mds.870100319

120. Suzuki Y, Kiyosawa M, Ohno N, Michizuki M, Inaba A, Mizusawa H, et al. Gluocse hypometablism in medial frontal cortex of patients with apraxia of lid opening. Graefes Arch Clin Exp Ophthalmol (2003) 241(7):529-34. doi:10.1007/s00417-003-0682-0
121. Defazio G, Livrea P, Lamberti P, De Salvia R, Laddomada G, Giorelli $\mathrm{M}$, et al. Isolated so-called apraxia of eyelid opening: report of 10 cases and a review of the literature. Eur Neurol (1988) 39:204-10. doi:10.1159/000007935

122. Aramideh M, Eekhof JL, Bour LJ, Koelman JH, Speelman JD, Ongerboer de Visser BW. Electromyography and recovery of the blink reflex in involuntary eyelid closure: a comparative study. J Neurol Neurosurg Psychiatry (1995) 58(6):692-8.

123. Rana AQ, Kabir A, Dogu O, Patel A, Khondker S. Prevalence of blepharospasm and apraxia of eyelid opening in patients with parkinsonism, cervical dystonia, and essential tremor. Eur Neurol (2012) 68(5):318-21. doi:10.1159/000341621

124. Esposito M, Fasano A, Crisci C, Dubbioso R, Iodice R, Santoro L. The combined treatment with orbital and pretarsal bnotulinum toxin injections in the management of poorly responsive blepharospasm. Neurol Sci (2014) 35(3):397-400. doi:10.1007/s10072-013-1526-2

125. Tozlovanu V, Forget R, Iancu A, Boghen D. Prolonged orbicularis oculi activity: a major factor in apraxia of lid opening. Neurology (2001) 57(6):1013-8. doi:10.1212/WNL.57.6.1013

126. Lamberti P, De Mari M, Zenzola A, Aniello MS, Defazio G. Frequency of apraxia of eyelid opening in the general population and in patients with extrapyramidal disorders. Neurol Sci (2002) 23:S81-2. doi:10.1007/ s100720200080

127. Nath U, Ben-Shiomo Y, Thomson RG, Lees AJ, Burn DJ. Clinical features oand natural history of progressive supranuclear palsy: a clinical cohort study. Neurology (2003) 60(6):910-6. doi:10.1212/01.WNL.0000052991.70149.68

128. Ouchi H, Toyoshima Y, Tada M, Oyake M, Aida I, Tomita I, et al. Pathology and sensitivity of current clinical criteria in corticobasal syndrome. Mov Disord (2014) 29(2):238-44. doi:10.1002/mds.25746

129. Kanazawa M, Thimohata T, Sato M, Onodera O, Tanaka K, Nishizawa M. Botulinum toxin A injections improve apraxia of eyelid opening without overt blepharospasm associated with neurodegenerative diseases. Mov Disord (2007) 22(4):597-8. doi:10.1002/mds.21367

130. Cardoso F, de Oliveira JT, Puccioni-Sohler M, Fernandes AR, de Mattos JP, Lopes-CendesI.Eyeliddystoniain Machado-Joseph disease.MovDisord (2000) 15(5):1028-30. doi:10.1002/1531-8257(200009)15:5<1028::AIDMDS1047>3.0.CO;2-\#

131. Cherian V, Foroozan R. Benign unilateral apraxia of eyelid opening. Ophthalmology (2010) 117(6):1265-8. doi:10.1016/j.ophtha.2009.10.032

132. Della Marca G, Losurdo A, Cordone S, Pilato F, Profice P, Testani E, et al. Teaching NeuroImages: awakening ptosis (unilateral hypnopompic eyelid palsy). Neurology (2013) 81(10):e71-2. doi:10.1212/ WNL.0b013e3182a351e7

133. Aramideh M, Kwa IH, Brans JW, Speelman JD, Verbeeten B Jr. Apraxia of eyelid closure accompanied by denial of eye opening. Mov Disord (1997) 12(6):1105-8. doi:10.1002/mds.870120651

134. Bonelli RM, Niederwieser G. Apraxia of eyelid closure in Huntington's disease. J Neural Transm (2002) 109(2):197-201. doi:10.1007/s007020200016

135. Fukishima T, Hasegawa A, Matsubara N, Kolke R. An apraxia of eyelid closure in association with frontal lobe atrophy in a patient with amyotrophic lateral sclerosis. Rinsho Shinkeigaku (2007) 47(5):226-30.

136. Hirayama M, Kumano T, Aita T, Nakagawa H, Kuriyama M. Improvement of apraxia of eyelid opening by wearing goggles. Lancet (2000) 356(9239):1413. doi:10.1016/S0140-6736(00)02851-8

137. Ramasamy B, Rowe F, Freeman G, Owen M, Noonan C. Modified Lundie loops improve apraxia of eyelid opening. JNeuroophthalmol (2007) 27(1):32-5. doi:10.1097/WNO.0b013e3180334fob

138. Dewey RB Jr, Maraganore DM. Isolated eyelid-opening apraxia: report of a new levodopa-responsive syndrome. Neurology (1994) 44(9):1752-4. doi:10.1212/WNL.44.9.1752

139. Yamada S, Matsuo K, Hirayama M, Sobue G. The effects of levodopa on apraxia of lid opening: a case report. Neurology (2004) 62(5):830-1. doi:10.1212/01.WNL.0000113751.19247.84

140. Lee KC, Finley R, Miller B. Apraxia of lid opening: dose-dependent response to carbidopa-levodopa. Pharmacotherapy (2004) 24(3):401-3. doi:10.1592/ phco.24.4.401.33174

141. Krack P, Marion MH. "Apraxia of lid opening," a focal eyelid dystonia: clinical study of 32 patients. Mov Disord (1994) 9(6):610-5. doi:10.1002/ mds. 870090605 
142. Tokisato K, Fukunaga K, Tokunaga M, Watanabe S, Nakanishi R, Yamanaga H. Aripiprazole can improve apraxia of eyelid opening in Parkinson's disease. Intern Med (2015) 54(23):3061-4. doi:10.2169/internalmedicine. 54.4279

143. Eftekhari K, Choe CH, Vagefi MR, Gausas RE, Eckstein LA. Oral methylphenidate for the treatment of refractory facial dystonias. Ophthal Plast Reconstr Surg (2015) 31(3):e65-6. doi:10.1097/IOP.0000000000000079

144. Piccione F, Mancini E, Tonin P, Bizzarini M. Botulinum toxin treatment of apraxia of eyelid opening in progressive supranuclear palsy: report of two cases. Arch Phys Med Rehabil (1997) 78(5):525-9. doi:10.1016/ S0003-9993(97)90169-6

145. Georgescu D, Vagefi MR, McMullan TF, McCann JD, Anderson RL. Upper eyelid myectomy in blepharospasm with associated apraxia of lid opening. Am J Ophthalmol (2008) 145(3):541-7. doi:10.1016/j.ajo.2007.10.017

146. Dressler D, Karapantzou C, Rohrbach S, Schneider S, Laskawi R. Frontalis suspension surgery to treat patients with blepharospasm and eyelid opening apraxia: long term results. J Neural Transm (2017) 124(2):253-7. doi:10.1007/ s00702-016-1641-3

147. De Groot V, De Wilde F, Smet L, Tassignon MJ. Frontalis suspension combined with blepharoplasty as an effective treatment for blepharospasm associated with apraxia of eyelid opening. Ophthal Plast Reconstr Surg (2000) 16(1):34-8. doi:10.1097/00002341-200001000-00006

148. Baizabal-Carvallo JF, Jankovic J. Movement disorders induced by deep brain stimulation. Parkinsonism Relat Disord (2016) 25:1-9. doi:10.1016/j. parkreldis.2016.01.014

149. Tommasi G, Krack P, Fraix V, Pollak P. Effects of varying subthalamic nucleus stimulation on apraxia of lid opening in Parkinson's disease. J Neurol (2012) 259(1944):2592. doi:10.1007/s00415-012-6447-0

150. Umemura A, Toyoda T, Yamamoto K, Oka Y, Ishii F, Yamada K. Apraxia of eyelid opening after subthalamic deep brain stimulation may be caused by reduction of levodopa. Parkinsonism Relat Disord (2008) 14(8):655-7. doi:10.1016/j.parkreldis.2007.12.008

151. Weiss D, Wächter T, Breit S, Jacob SN, Pomper JK, Asmus F, et al. Involuntary eyelid closure after STN-DBS: evidence for different pathophysiological entities. JNeurol Neurosurg Psychiatry (2010) 81:1002-7. doi:10.1136/ jnnp.2009.196691

152. Fuss G, Spiegel J, Magnus T, Moringlane JR, Becker G, Dillmann U. Improvement of apraxia of lid opening by STN-stimulation in a 70 year-old with Parkinson's disease: a case report. Minim Invasive Neurosurg (2004) 47(1):58-60. doi:10.1055/s-2003-812466

153. Goto S, Kihara K, Hamasaki T, Nishikawa S, Hirata Y, Ushio Y. Apraxia of lid opening is alleviated by pallidal stimulation in a patient with Parkinson's disease. Eur JNeurol (2000) 7(3):337-40. doi:10.1046/j. 1468-1331.2000.00058.x

154. Skarf B. Normal and abnormal eyelid function. In: Miller NR, Newman NJ, Biousse V, Kerrison JB, editors. Walsh \& Hoyt's Clinical NeuroOphthalmology. Philadelphia, PA: Lippincott, Williams, \& Wilkins (2004). p. $1177-229$.

Conflict of Interest Statement: The authors declare that the research was conducted in the absence of any commercial or financial relationships that could be construed as a potential conflict of interest.

Copyright (c) 2017 Hamedani and Gold. This is an open-access article distributed under the terms of the Creative Commons Attribution License (CC BY). The use, distribution or reproduction in other forums is permitted, provided the original author(s) or licensor are credited and that the original publication in this journal is cited, in accordance with accepted academic practice. No use, distribution or reproduction is permitted which does not comply with these terms. 